\title{
Serum 25-hydroxyvitamin D levels in children with recurrent wheezing and relation to the phenotypes and frequency of wheezing
}

${ }^{1}$ Zeynep Kamil Woman and Children’ Diseases Training and Research Hospital, Department of Pediatrics, Istanbul, Turkey

\section{KeY Words}

wheezing; vitamin D; child;

episodes; phenotype

\section{Corresponding author}

Mahmut Doğru

Zeynep Kamil Woman and Children'

Diseases Training and Research Hospital

Department of Pediatrics, Burhanettin

Ustunel Cad. 10

Uskudar, Istanbul, Turkey

Phone: +90 5052703514

Fax: +902163910699

E-mail: mdmahmut@yahoo.com

\section{Doi}

10.23822/EurAnnACI.1764-1489.14

\begin{abstract}
Summary
Background. Recurrent wheezing may be related to various reasons. There is a lack of knowledge about the effect of vitamin D status in the children with recurrent wheezing. The aim of this study is to compare the level of vitamin D between recurrent wheezing children and healthy controls, and to investigate the relationship between vitamin D status and the clinical parameters of recurrent wheezing in preschool children. Methods. One hundred-ten children followed up in our hospital with recurrent wheezing were included in the study. The control group included fifty children without wheezing episodes. The serum 25-hydroxyvitamin D (25OHD) level was measured. The patients with recurrent wheezing were grouped according to their vitamin D status as "deficient group" and "non-deficient group (Vitamin D level is insufficient and normal)". We investigated the relationship between vitamin D status and the clinical and laboratory parameters of children with recurrent wheezing. Results. Mean $25 \mathrm{OHD}$ level was $21.66 \pm 8.13 \mathrm{ng} / \mathrm{mL}(5.6-53)$ in the study group and $25.36 \pm 10.17 \mathrm{ng} /$ $m L(6-59)$ in the control group. The difference was statistically significant $(p=0.015)$. When the patients with recurrent wheezing were compared according to their vitamin D status, number of hospitalizations, number of positive sensitivity, percentage of eosinophil, serum IgE levels, Asthma Predictive Index positivity and wheezing phenotypes were not found to be different between groups. However, the duration of wheezing, the number of wheezing episodes and systemic glucocorticoid need in the previous year, and the total number of wheezing episodes were significantly higher in the deficient group $(p<0.05)$. The serum $250 H D$ level was negatively correlated with the duration of wheezing ( $r:-0.238$; $p: 0.012)$, total number of wheezing episodes ( $r$ :-0.436; $p: 0.001)$, number of wheezing episodes in the previous year ( $r$ : -0.395; $p: 0.001$ ), and systemic glucocorticoid need in the previous year ( $r:-0.324 ; p: 0.001$ ). Conclusions. Mean 25OHD levels were lower in patients with recurrent wheezing than in healthy controls. The duration of illness and number of wheezing episodes were correlated with vitamin $D$ levels. An evaluation of the serum levels of vitamin $D$ and supplementation if needed should be recommended in patients with recurrent wheezing, especially in those with long-term and frequent wheezing episodes.
\end{abstract}




\section{Introduction}

Wheezing is one of the most common respiratory symptoms in the childhood. Allergic sensitization in early life, infection with rhinovirus, or colonization with any of a number of bacteria have been associated with increased risk of persistent wheeze. Acute respiratory infection is the main cause of recurrent wheezing in children. Respiratory viruses play a key role in the development and exacerbation of obstructive respiratory diseases in children $(1,2)$. Recent studies showed that vitamin D acts as a hormone and takes a role in the function of many organs in addition to bone. Vitamin D deficiency predisposes to infections by affecting the production of antimicrobial peptides such as Cathelicidin. The antimicrobial activity against airway pathogens is increased with vitamin $\mathrm{D}$ treatment because of antimicrobial cationic peptides, defensin-beta- 2 and 4 regulated by vitamin D. 1,25-dihydroxyvitamin $\mathrm{D}$ is the active form of vitamin $\mathrm{D}$. 1,25-dihydroxyvitamin $\mathrm{D}$ decreased proliferation of Th1 and Th2 cells, and production of interferon (IFN)- $\gamma$, interleukin (IL)-2 and IL-5. But IL-4 production is increased by 1,25 -dihydroxyvitamin $\mathrm{D}(3,4)$. Previous studies have shown that low serum 25-hydroxyvitamin D (25OHD) levels are associated with increased risk of respiratory tract infections in children and adults (5-7). There are some studies supporting the relationship between vitamin $\mathrm{D}$ deficiency and recurrent wheezing in childhood (7-11) as well as studies showing no relationship (12) or negative relationship (13). We aimed to compare the level of vitamin $\mathrm{D}$ between children with recurrent wheezing and healthy controls, and to investigate the relationship between vitamin D status and the clinical parameters of recurrent wheezing in preschool children.

\section{Materials and methods}

A total of 160 children (64 girls, 96 boys; aged $0.75-5$ years) enrolled in the study. The study was approved by the local ethics committee of the same institute and adhered to the principles of Helsinki Declaration. A consent was obtained from all subjects and/ or their parents.

\section{Study Population}

One hundred-ten children with recurrent wheezing who started before 3 years and had more than 3 wheezing episodes were included in the study. The control group consisted of fifty children without wheezing episodes or any chronic disease. Children were evaluated in September 2012-February 2013 and September 2013-February 2014, in order to exclude the seasonal differences. The patients' age, gender, exposure to smoke, personal/ familial atopy and wheezing history were recorded. Presence of atopy in the family was considered as positive if a first-degree relative (mother, father, sibling) had allergic disease. Milk consumption of cases was not evaluated, because milk is not fortified with vitamin $\mathrm{D}$ in our country. The percentage of eosinophils, immunoglobulin (Ig) E levels and serum 25OHD levels were measured. RW patients were classified according to the number of wheezing episodes in the previous year as having had up to 3 episodes / year $(n=61)$ or $>3$ episodes / year $(n=49)$.

\section{Excluding Criteria}

Patients receiving multivitamin support or any systemic glucocorticoid therapy, patients with obesity (body mass index > 95.p), patients with the clinical findings of rickets (o-bain, $\mathrm{x}$-bain etc.), with any (clinical or laboratory) history of congenital heart disease, chronic lung disease (such as cystic fibrosis, bronchiectasis), tuberculosis, bronchopulmonary dysplasia, immunodeficiency, neurologic or metabolic diseases were excluded.

\section{The phenotyping of wheezing}

The Asthma Predictive Index (API) is an index used to evaluate the risk of developing asthma in the future with children who had recurrent wheeze. The major criteria are physician-diagnosed asthma in parents and atopic dermatitis in the child. The minor criteria are eosinophilia $(>4 \%)$, physician diagnosed allergic rhinitis and wheezing without upper respiratory tract infection in the child. It was considered positive when at least one major or two minor criteria were present (14).

In another phenotyping of wheezing, children were classified as having either episodic wheezing (EW) (wheezing only during colds and remaining asymptomatic between episodes) or multiple-trigger wheezing (MTW) (wheezing during colds but symptomatic between episodes, with wheezing activated by factors such as house dust, tobacco smoke, exercise, crying, laughter, or odor) (15).

\section{Skin Prick Tests}

Skin prick tests were applied on the anterior forearm. Patients were considered eligible for the skin test if they had not received antihistamines for at least one week. Skin prick tests for common aeroallergens (Dermatophagoides pteronyssinus, Dermatophagoides farinea, mixture of grass pollens, a mixture of grain pollens (oats, wheat, barley, corn), a mixture of tree pollens, weed-mix pollens, Alternaria alternaria, cockroaches (Blatella germanica), cat dander and dog dander (Stallergenes SA, 92160 Antony, France) were performed by using Stallerpoint ${ }^{\circledR}$ (Stallergenes SA, 92160 Antony, France). Histamine $(10 \mathrm{mg} / \mathrm{ml})$ and physiological saline were used as positive and negative references, respectively. Skin reactions were evaluated at 20th minute of the application. A positive reaction was characterized as $3 \mathrm{~mm}$ 
or greater than that of the negative control. Atopy was classified as at least 1 positive response to these allergens with no response to negative reference solution and a response to positive reference (histamine).

\section{Vitamin D Levels}

Vitamin D levels were measured 2 weeks after any infection. Peripheral venous blood samples were obtained from all children and serum $25 \mathrm{OHD}$ levels were measured by using liquid chromatography-tandem mass spectrometry (LC-MS-MS) method in Waters Quattro Premier XETM (Waters Corp. Milford, USA). Serum $25 \mathrm{OHD}$ levels $\leq 20 \mathrm{ng} / \mathrm{mL}$ were considered as vitamin D deficiency, while levels between 20 and $29 \mathrm{ng} / \mathrm{mL}$ as vitamin $\mathrm{D}$ insufficiency, $30-80 \mathrm{ng} / \mathrm{mL}$ as optimal vitamin $\mathrm{D}$ level and $\geq 80 \mathrm{ng} / \mathrm{mL}$ as potential vitamin D toxicity (16). The patients with recurrent wheezing were grouped according to their vitamin D status as "deficient group" and "non-deficient group (Vitamin D levels insufficient and normal)".

\section{Statistical Analyses}

Data was analyzed by using the Statistical Package for Social Sciences (SPSS) for Windows (SPSS 15.0 Chicago, USA) program. Values for continuous variables were given as either mean \pm standard deviation or as median (interquartile range), based on the normality of distribution. Student $t$ test was used for the comparison of normally distributed variables. Mann-Whitney $\mathrm{U}$ test was used for non-normally distributed variables. ChiSquare test was used to compare categorical variables. Pearson's correlation test was used for the correlation analyses of continuous variables. $p<0.05$ was considered as significant.

\section{Results}

A total of 160 children were enrolled in this study. The study group consisted of 110 children (mean age: $2.97 \pm 1.26$ years; 69 boys and 41 girls) and control group were 50 children without wheezing episodes (mean age: $2.89 \pm 1.27$ years; 27 boys and 23 girls). There were no statistically significant differences in regards to age and gender between patients and control groups. Mean $25 \mathrm{OHD}$ level was $21.66 \pm 8.13 \mathrm{ng} / \mathrm{mL}$ (5.6$53)$ in the study group and $25.36 \pm 10.17 \mathrm{ng} / \mathrm{mL}(6-59)$ in the control group. The difference was statistically significant $(\mathrm{p}$ $=0.015)$. Vitamin D status was determined as deficient in 50 (45.5\%) patients, and non-deficient (insufficiency or normal) in $60(54.5 \%)$ of the study group, while deficient in $14(28 \%)$ and non-deficient in $36(72 \%)$ of the control group. Vitamin $\mathrm{D}$ status was found to be different between groups $(\mathrm{p}=0.039)$. When patients are grouped by API positivity; although mean $25 \mathrm{OHD}$ level in API negative group was lower than API positive group, this difference was not statistically significant (81 patients, $21.43 \pm 8.78 \mathrm{ng} / \mathrm{mL}$ vs 29 patients, $22.30 \pm 6.02 \mathrm{ng} / \mathrm{mL} ; \mathrm{p}=$ $0.623)$. Similarly, when the patients were grouped in terms of 25 OHD level according to the wheezing phenotypes (EW or MTW), there was no difference between groups (51 patients, $22.78 \pm 9.08$ $\mathrm{ng} / \mathrm{mL}$ vs 59 patients, $20.69 \pm 7.14 \mathrm{ng} / \mathrm{mL} ; \mathrm{p}=0.342$ ).

The patients with recurrent wheezing were grouped according to their vitamin D status as "deficient (Group-I)" and "non-deficient (Group-II)". No statistically significant difference was present between groups in terms of gender, age, familial atopy, and exposure to smoke ( $\mathrm{p}>0.05)$ (table 1).

The number of hospitalizations, number of positive sensitivity, percentage of eosinophils, and serum IgE levels were not found to be different between groups. However, the duration of wheezing, the number of wheezing episodes and systemic glucocorticoid need in the previous year and the total number of wheezing episodes were significantly different between groups $(\mathrm{p}<0.05)$ (table 1).

When patients compared according to the number of wheezing episodes in the previous year ( $\leq 3$ episodes/years and $>3$ episodes / years), the mean vitamin D level was significantly lower in patients with $>3$ episodes/years ( 49 patients, $19.36 \pm 7.72$ $\mathrm{ng} / \mathrm{mL}$ vs 61 patients, $23.50 \pm 8.04 \mathrm{ng} / \mathrm{mL} ; \mathrm{p}=0.007)$.

Eighty patients (72.7\%) of study group underwent to skin prick test. Mean $25 \mathrm{OHD}$ level was $20.86 \pm 6.2 \mathrm{ng} / \mathrm{mL}$ in atopic children and $20.81 \pm 8.53 \mathrm{ng} / \mathrm{mL}$ in non-atopic children. The difference was not statistically significant $(\mathrm{p}=0.977)$. Vitamin D status was not found to be different between atopic children and non-atopic children $(\mathrm{p}=0.653)$ (table $\mathbf{1})$.

The serum 25OHD level was negatively correlated with the duration of wheezing ( $r:-0.238$; p: 0.012), total number of wheezing episodes (r: -0.436; p: 0.001), number of wheezing episodes (r: -0.395; p: 0.001) and systemic glucocorticoid need in the previous year (r: -0.324; p: 0.001).

\section{Discussion}

This study showed that mean 25OHD levels of children with recurrent wheezing is lower than healthy control group. This result is similar to the results of previous studies (7-11). The study of Bener et al (7) compared vitamin D status of allergic and healthy children and found that the frequency of severe vitamin $\mathrm{D}$ deficiency was significantly higher in children with wheezing $(23.4 \%)$ than in healthy children $(10.5 \%)$. They indicated that vitamin $\mathrm{D}$ deficiency was a significant risk factor for wheezing (relative risk $=1.29 ; p=0.05$ ). Similar results were found in the other studies (8-11). However, another study (12) compared vitamin D levels of 30 children with recurrent wheezing and 45 healthy children, and significant difference between groups were not found. The reason for the difference of the results of this study may be the small number of cases and age of the patients. 
Table 1 - Comparison of socio-demographic, clinical and laboratory findings features of the vitamin D deficient (Group-I), vitamin D non-deficient (Group-II) patients' groups.

\begin{tabular}{|c|c|c|c|}
\hline & $\begin{array}{c}\text { Group I } \\
\mathrm{n}: 50\end{array}$ & $\begin{array}{c}\text { Group II } \\
\text { n: } \mathbf{6 0}\end{array}$ & $\mathbf{p}$ \\
\hline Gender (Male/Female) & $32 / 18$ & $37 / 23$ & $0.845^{1}$ \\
\hline Age (years) $)^{\ddagger}$ & $3.1 \pm 1.8$ & $2.9 \pm 1.3$ & $0.303^{2}$ \\
\hline Familial atopy n (\%) & $15(30)$ & $24(40)$ & $0.320^{1}$ \\
\hline Exposure to smoke n (\%) & $26(52)$ & $33(55)$ & $0.848^{1}$ \\
\hline Duration of disease (Month) ${ }^{*}$ & $24(15.5-30)$ & $18(12-25)$ & $0.037^{3}$ \\
\hline Total numbers of wheezing episodes* & $6(5-10)$ & $4(3-5)$ & $0.001^{3}$ \\
\hline Numbers of hospitalizations ${ }^{*}$ & $0(0-1)$ & $0(0-0)$ & $0.100^{3}$ \\
\hline Systemic glucocorticoid need in the previous year ${ }^{*}$ & $1(0-2)$ & $0(0-1)$ & $0.001^{3}$ \\
\hline Numbers of wheezing episodes in the previous year ${ }^{*}$ & $3(2-5)$ & $3(2-3.5)$ & $0.011^{3}$ \\
\hline The percentage of eosinophils $(\%)^{*}$ & $2(1.4-3.5)$ & $2.6(1.3-5.2)$ & $0.052^{3}$ \\
\hline Immunoglobulin $\mathrm{E}(\mathrm{IU} / \mathrm{ml})^{*}$ & $70(29-352)$ & $56(32-156)$ & $0.651^{3}$ \\
\hline API positivity n (\%) & $11(22)$ & $18(30)$ & $0.390^{1}$ \\
\hline $\begin{array}{l}\text { Phenotyping of wheezing n (\%) } \\
\text { Episodic wheezing } \\
\text { Multiple-triggered wheezing }\end{array}$ & $\begin{array}{l}24(48) \\
26(52)\end{array}$ & $\begin{array}{l}27(45) \\
33(55)\end{array}$ & $0.848^{1}$ \\
\hline Sensitivity in skin prick test (atopy) n (\%) & $19(48.8)$ & $17(41.5)$ & $0.653^{1}$ \\
\hline The number of positive sensitivity ${ }^{*}$ & $0(0-2)$ & $0(0-2)$ & $0.528^{3}$ \\
\hline
\end{tabular}

"Data are presented as either mean \pm Standard deviation or as median (interquartile range) according to the distribution.

${ }^{1}$ chi-square test ${ }^{2}$ Student $t$ test ${ }^{3}$ Mann-Whitney $U$ test

In another study, Pereira et al (13) assessed children with recurrent wheezing (RW) (n: 255) and occasional wheezing (OW) (n: 115). They observed significantly higher serum vitamin D levels in RW children than in OW children. This result is incompatible with our study. This difference may be related to the choice of patient. This study did not specify whether or not there were obese patients. In addition, the season of vitamin D measurement is uncertain in the study.

Vitamin D deficiency is an important health problem in both developed and developing countries. In this study $44.5 \%$ of children with recurrent wheezing was found to be vitamin D deficient while $28 \%$ of control group was vitamin $\mathrm{D}$ deficient. It was shown that vitamin $\mathrm{D}$ deficiency is a common problem among children in our country (17). The high frequency of vitamin D deficiency in our country may be related to inadequate vitamin $\mathrm{D}$ supplementation during infancy, low levels of vitamin $\mathrm{D}$ in pregnancy, scarcity of vitamin D fortified food products, and frequent respiratory tract infections.

The results of studies investigating vitamin D levels according to API and phenotypes of wheezing in children with RW are inconsistent $(9,11)$. In a cross sectional study, the investigators reported a correlation of low levels of vitamin $\mathrm{D}$ in patients with RW, API positive and multi-trigger temporal pattern of wheeze compared with non-recurrent wheezing, API negative and episodic temporal pattern of wheeze. In a recent study in Turkey, Ozdemir et al (11) found that the API negative group had the lowest mean serum $25(\mathrm{OH}) \mathrm{D}$ level, followed by API positive group compared to healthy group ( $\mathrm{p}<0.05)$. These differences in studies may depend on such factors as patient selection, age, time, method of measurement.

Another remarkable result of present study is the duration of wheezing, the high total number of wheezing episodes, number of wheezing episodes and systemic glucocorticoid need in the previous year among the vitamin $\mathrm{D}$ deficient wheezy children comparing to vitamin D non-deficient wheezy children. In addition, we found a negative correlation between these parameters and vitamin D levels. Uysalol et al (9) declared a negative correlation between vitamin $\mathrm{D}$ levels and the number of wheezing episodes, hospitalization and admission to emergency department in the previous year $(\mathrm{r}:-0.394 \mathrm{p}=0.010, \mathrm{r}=-0.406 \mathrm{p}$ 
Figure 1 - Distribution of the duration of wheezing, total numbers of wheezing episodes, numbers of wheezing episodes and systemic glucocorticoid need in the previous year with regard to vitamin D levels.
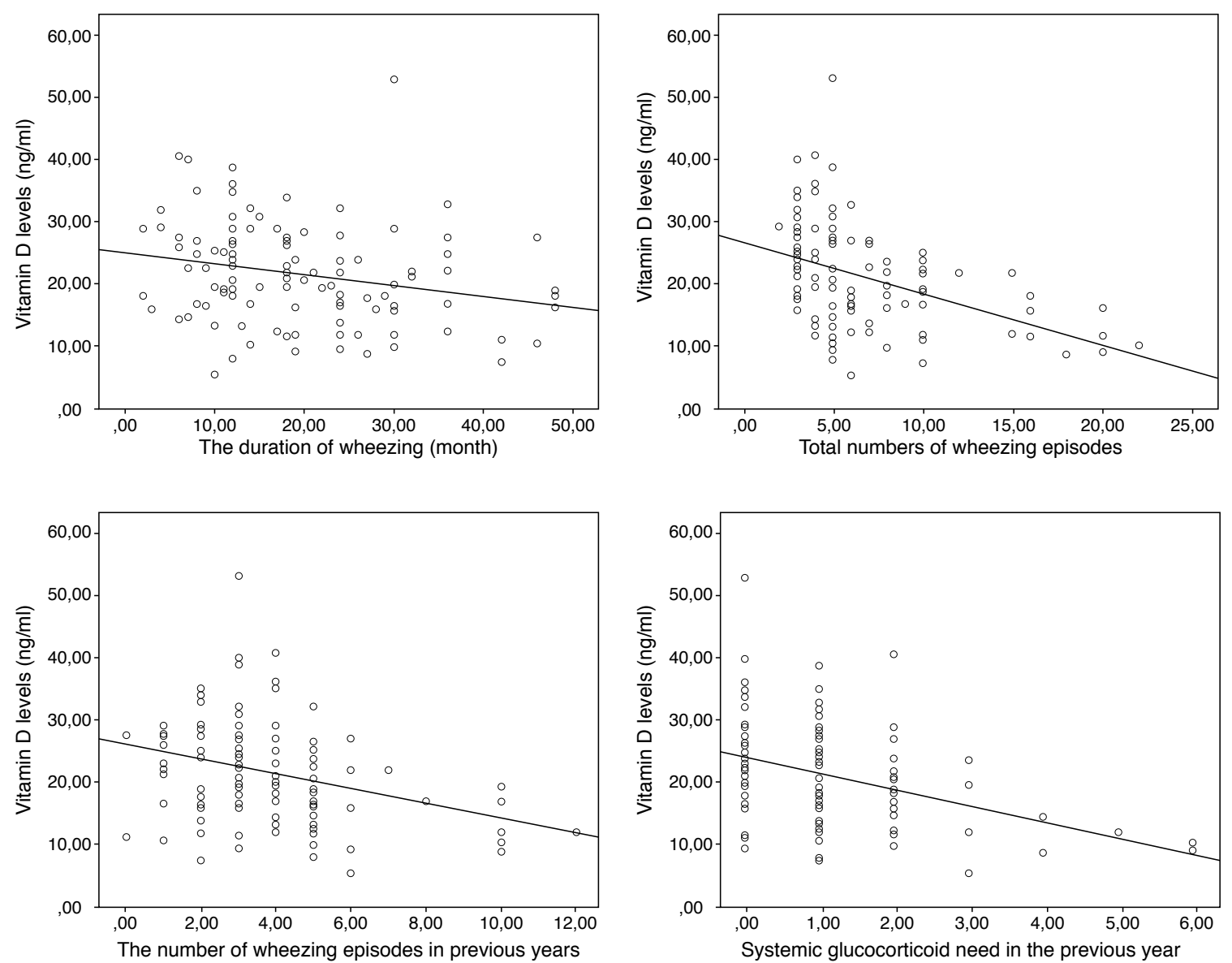

$<0.001, r=0.307 \mathrm{p}=0.008$, respectively). Systemic steroid requiring episodes were not evaluated in this study, while Beigelman et al (18) reported an increased number of steroid requiring episodes in children with decreased vitamin D level. Increased frequency and severity of wheezing episodes in vitamin $\mathrm{D}$ deficient might be due to several reasons. Firstly, as mentioned above, increased frequency of respiratory infections is associated with vitamin D deficiency (5-7). Vitamin D deficiency has also been seen to correlate with an increased risk of respiratory viral co-infections, especially Respiratory syncytial virus and Rhinovirus infections. These viruses are considered the main triggers of childhood wheezing (19). Secondly, vitamin D has complex immunomodulatory properties for both innate and adaptive immune system functions as well as in calcium / phosphorus homeostasis and bone health. Vitamin D is implicated in fetal lung growth and maturation (20). There is also evidence of a role of vitamin $\mathrm{D}$ in maintaining lung structure and pulmonary function (21). Decreased lung maturation due to prematurity is a risk factor for recurrent wheezing. Because of vitamin D deficiency making deterioration in lung maturation and function, these patients are expected to have more frequent episodes wheezing. Third reason might be the suppressive effect of vitamin $\mathrm{D}$ on inflammation and airway hyper-responsiveness, by inhibiting synthesis and releasing inflammatory cytokines from bronchial smooth muscle cells. Vitamin D also promotes T-regulatory cell activity (22). Wheezing can occur more frequently due to the increased on inflammation and airway hyper-responsiveness caused by vitamin $\mathrm{D}$ deficiency.

Limited participant number was the negative aspect of our study. It was designed as a single-center study including $0.75-5$ years old patients with RW. Vitamin D levels were measured in a single sample obtained in autumn or winter. More than one 
sample could have been obtained and mean vitamin D levels throughout the year could have been measured in order to minimize the seasonal differences.

As a result, mean 25OHD levels were lower in patients with recurrent wheezing than healthy controls. The duration of illness and number of wheezing episodes were correlated with vitamin D levels. Evaluation of the serum levels of vitamin D and supplementation if needed should be recommended in patients with recurrent wheezing, especially in patients with long-term and frequent wheezing episodes.

\section{References}

1. Grad R, Morgan WJ. Long-term outcomes of early-onset wheeze and asthma. J Allergy Clin Immunol. 2012;130(2):299-307.

2. Takeyama A, Hashimoto K, Sato M, Sato T, Tomita Y, Maeda R, Ito M, Katayose M, Kawasaki Y, Hosoya M. Clinical and epidemiologic factors related to subsequent wheezing after virus-induced lower respiratory tract infections in hospitalized pediatric patients younger than 3 years. Eur J Pediatr. 2014;173(7):959-66.

3. Yim S, Dhawan P, Ragunath C, Christakos S, Diamond G. Induction of cathelicidin in normal and CF bronchial epithelial cells by 1,25-dihydroxyvitamin D3. J Cyst Fibros. 2007;6(6):403-10.

4. Dimeloe S, Nanzer A, Ryanna K, Hawrylowicz C. Regulatory T cells, inflammation and the allergic response-The role of glucocorticoids and vitamin D. J Steroid Biochem Mol Biol. 2010;120:86-95.

5. Ginde AA, Mansbach JM, Camargo CA Jr. Association between serum 25- hydroxyvitamin D level and upper respiratory tract infection in the Third National Health and Nutrition Examination Survey. Arch Intern Med. 2009;169:384-90.

6. Laaksi I, Ruohola JP, Tuohimaa P, Auvinen A, Haataja R, Pihlajamaki H, Ylikomi T. An association of serum vitamin D concentrations $<40 \mathrm{nmol} / \mathrm{L}$ with acute respiratory tract infection in young Finnish men. Am J Clin Nutr. 2007;86:714-7.

7. Bener A, Ehlayel MS, Bener HZ, Hamid Q. The impact of Vitamin D deficiency on asthma, allergic rhinitis and wheezing in children: An emerging public health problem. J Family Community Med. 2014;21(3):154-61.

8. Ture M, Zeyrek CD, Koçyigit A. Serum vitamin D, folic acid and B12 levels in wheezy children. Asthma Allergy Immunol. 2013;11:169-77.

9. Uysalol M, Uysalol EP, Yilmaz Y, Parlakgul G, Ozden TA, Ertem HV, Omer B, Uzel N. Serum level of vitamin D and trace elements in children with recurrent wheezing: a cross-sectional study. BMC Pediatr. 2014;14(1):270.
10. Demirel S, Guner SN, Celiksoy MH, Sancak R. Is vitamin D insufficiency to blame for recurrent wheezing? Int Forum Allergy Rhinol. 2014;4(12):980-5.

11. Ozdemir A, Dogruel D, Yilmaz O. Vitamin D Status in Infants with Two Different Wheezing Phenotypes. Indian J Pediatr. 2016;83(12-3):1386-91.

12. Özaydın E, Bütün MF, Cakır BC, Köse G. The association between vitamin $\mathrm{D}$ status and recurrent wheezing. Indian J Pediatr. 2013;80(11):907-10.

13. Urrutia-Pereira M, Solé D. Is Vitamin D Deficiency a Marker of Severity of Wheezing in Children? A Cross-sectional Study. J Investig Allergol Clin Immunol. 2016;26(5):319-21.

14. Castro-Rodríguez JA, Holberg CJ, Wright AL, Martinez FD: A clinical index to define risk of asthma in young children with recurrent wheezing. Am J Respir Crit Care Med. 2000, 162:1403-6.

15. Brand PL, Baraldi E, Bisgaard H, et al. Definition, assessment and treatment of wheezing disorders in preschool children: an evidence-based approach. Eur Respir J. 2008;32:1096-110.

16. Ross AC, Manson JE, Abrams SA, Aloia JF, Brannon PM, Clinton SK, Duraz0-Arvizu RA, Gallagher JC, Gallo RL, Jones G, et al. The 2011 report on dietary reference intakes for calcium and vitamin D from the Institute of Medicine: What clinicians need to know. JCEM. 2011;96:53-8.

17. Andıran N, Çelik N, Akça H, Doğan G. Vitamin D deficiency in children and adolescents. J Clin Res Pediatr Endocrinol. 2012;4(1):25-9.

18. Beigelman A, Zeiger RS, Mauger D, Strunk RC, Jackson DJ, Martinez FD, Morgan JW, Covar R, Szefler SJ, Taussing LM, et al. Childhood Asthma Research and Education (CARE) Network of the National Heart, Lung, and Blood Institute. The association between vitamin D status and the rate of exacerbations requiring oral corticosteroids in preschool children with recurrent wheezing. J Allergy Clin Immunol. 2014;133(5):1489-92.

19. Jartti T, Ruuskanen O, Mansbach JM, Vuorinen T, Camargo CA Jr. Low serum 25-hydroxyvitamin D levels are associated with increased risk of viral coinfections in wheezing children. J Allergy Clin Immunol. 2010;126(5):1074-6.e1-4.

20. Sakurai R, Shin E, Fonseca S, Sakurai T, Litonjua AA, Weiss ST, Torday JS, Rehan VK. 1alpha,25(OH)2D3 and its 3-epimer promoter at lung alveolar epithelial-mesenchymal interactions and inhibit lipofibroblast apoptosis. Am J Physiol Lung Cell Mol Physiol. 2009;297(3):496-505.

21. Zosky GR, Berry LJ, Elliot JG, James AL, Gorman S, Hart PH. Vitamin D deficiency causes deficits in lung function and alters lung structure. Am J Respir Crit Care Med. 2011;183(10):1336-43.

22. MS Sandhu, TB Casale: The role of vitamin D in asthma. Ann Allergy Asthma Immunol. 2010;105(3):191-9. 